\title{
Endogenous Nampt upregulation is associated with diabetic nephropathy inflammatory-fibrosis through the NF-кB p65 and Sirt1 pathway; NMN alleviates diabetic nephropathy inflammatory-fibrosis by inhibiting endogenous Nampt
}

\author{
YE CHEN $^{1^{*}}$, YUZHEN LIANG $^{2^{*}}$, TINGTING HU ${ }^{3 *}$, RIMING WEI $^{3}$, CONGJIE CAI $^{1}$, \\ PING WANG $^{1}$, LINGYU WANG ${ }^{1}$, WEI QIAO ${ }^{1}$ and LEPING FENG ${ }^{1}$ \\ ${ }^{1}$ Department of Nutrition and Health, Public Health School, Guilin Medical University, Guilin, \\ Guangxi 541004; ${ }^{2}$ Endocrinology Department, Diabetic Metabolic Center, First Affiliated Clinical Hospital, \\ Guangxi Medical University, Nanning, Guangxi 530021; ${ }^{3}$ Scientific Experiment Center, \\ Biotechnology School, Guilin Medical University, Guilin, Guangxi 541004, P.R. China
}

Received September 11, 2016; Accepted May 11, 2017

DOI: $10.3892 / \mathrm{etm} .2017 .5098$

\begin{abstract}
Nicotinamide phosphoribosyltransferase (Nampt) is a key enzyme in the nicotinamide adenine dinucleotide $\left(\mathrm{NAD}^{+}\right)$biosynthetic pathway. Exogenous extra cellular Nampt has been reported to increase the synthesis of pro-fibrotic molecules in various types of renal cells. However, the role of endogenous Namptenzymatic activity in diabetic renal cells, particularly those associated with inflammation and fibrosis through the nuclear factor (NF)-kB p65 and sirtuin 1 (Sirt1) pathway is still unknown. In the present study, a possible mechanism by which endogenous Nampt upregulation affects the expression of pro-inflammatory and pro-fibrotic cytokines in vivo and in vitro, is reported. The present results demonstrate that the expression of vimentin and fibronectin was directly implicated in endogenous Nampt upregulation. The expression levels of Poly(ADP-ribose) polymerase-1, NF- $\mathrm{B}$ p 65, forkhead box protein $\mathrm{O} 1$ and $\mathrm{B}$-cell lymphoma 2-like protein 4 were also significantly increased at $96 \mathrm{~h}$ compared with control group $(\mathrm{P}<0.01)$ respectively in response to endogenous Nampt upregulation. Furthermore, the expression level of Sirt1 was significantly reduced $(\mathrm{P}<0.05)$, and the NAD and NADH levels, and the NAD/NADH ratio are significantly altered in STZ-induced diabetic rats $(\mathrm{P}<0.01)$. Treatment with FK866
\end{abstract}

Correspondence to: Professor Leping Feng, Department of Nutrition and Health, Public Health School, Guilin Medical University, 109 North Ring 2nd Road, Guilin, Guangxi 541004, P.R. China

E-mail: lpfeng1226@sina.com

${ }^{*}$ Contributed equally

Key words: Nampt, nuclear factor- $\kappa \mathrm{B}$ p65, sirtuin 1, diabetic nephropathies, fibrosis, oxidative stress and nicotinamide mononucleotide (NMN) led to downregulation of vimentin and fibronectin, respectively. These results suggest a novel role of Nampt as a pro-inflammatory cytokine of mesangial fibrotic signaling. The Nampt-NF- $\mathrm{KB}$ p65 and Sirt1 signaling pathway serves a pivotal role in affecting the expression of fibrosis factors in diabetic nephropathy (DN) glomerular fibrosis processing. It is also suggested that prevention of endogenous Nampt upregulation may be critical in the treatment of DN pro-inflammatory fibrosis and NMN is likely to be a potential pharmacological agent for the treatment of resistant DN nephritic fibrosis.

\section{Introduction}

Diabetes mellitus (DM) is a major leading cause of end-stage renal failure, characterized by kidney inflammation and glomerular dysfunction, worldwide (1). Novel therapeutic targets for end-stage renal disease in diabetic nephropathy (DN) are urgently required (2). Recent studies have demonstrated that DN is characterized by an inflammatory response, which is associated with renal glomerular and tubular epithelial, endothelial, and interstitial cell apoptosis (3-6), which may be closely associated with inflammatory cell damage (7).

Nicotinamide phosphoribosyltransferase (Nampt) binds to and activates the insulin receptor and induces an insulin-like effect, both in vitro and in vivo (8). Notably, Nampt is a key enzyme in the nicotinamide adenine dinucleotide (NAD) ${ }^{+}$ biosynthetic pathway, where it acts as an adipokine and improves glucose tolerance via an insulin mimetic action $(6,8)$. Recent results have indicated that nuclear factor (NF)- $\mathrm{kB}$ signaling has a major role in innate immunity defense whereas sirtulin (SIRT)1 regulates the oxidative respiration and cellular survival (9). Additionally, NF- $\kappa$ B p65 signaling may stimulate glycolytic energy flux during acute inflammation, whereas SIRT1 activation inhibits NF- $\mathrm{kB}$ p65 signaling and enhances oxidative metabolism and reduces the expression of inflammatory and fibrotic factors, including tumor necrosis 
factor- $\alpha$ and transforming growth factor- $\beta$ ) (10). Previous findings have indicated that SIRT1 inhibits NF- $\mathrm{B}$ p65 signaling directly by deacetylating the p65 subunit of $\mathrm{NF}-\kappa \mathrm{B}$ complex (10). Furthermore, SIRT1 stimulates oxidative energy production via the activation of AMP-activated protein kinase, peroxisome proliferator-activated receptor- $\alpha$ and peroxisome proliferator-activated receptor gamma coactivator $1 \alpha$, and simultaneously, these factors inhibit NF- $\mathrm{B}$ p65 signaling and suppress inflammation (11). However, NF- $\mathrm{B}$ p65 signaling has also been indicated to downregulate SIRT1 activity through the expression of microRNA-34a, interferon- $\gamma$ and reactive oxygen species (12).

Exogenous extracellular Nampt has been reported to increase the synthesis of pro-fibrotic molecules in renal cell types (13). Although high glucose (HG) levels have been reported to increase endogenous Nampt expression in rat mesangial cells, murine podocytes, and tubular cells (14), the role of endogenous Nampt enzymatic activity in diabetic renal cells, particularly those associated with inflammation and fibrosis, is unknown beyond the regulation of glucose uptake.

The present study examined the molecular mechanisms of the antagonistic signaling between NF- $\kappa$ B p65 and SIRT1 and described how this crosstalk may control inflammatory process and how endogenous Nampt upregulation is associated in signaling crosstalk through promoting chronic inflammation in DN diseases.

\section{Materials and methods}

Animal models and groupings. Sprague-Dawley (SD) rats (male; aged 6-8 weeks old; weighing 200-250 g) were obtained from the Experimental Animal Center of Guilin Medical University (Guilin, China). Rats were housed in standard polypropylene cages and maintained under conditions of controlled room temperature $\left(23 \pm 1^{\circ} \mathrm{C}\right)$ and humidity (50-60\%) with a 12-h light/dark cycle. Rats received standard rat chow ad libitum throughout this study. A total of 80 rats were acclimatized for 1 week prior to random allocation into the control group $(n=30)$, which were fed a normal diet (regular chow comprising 5\% fat, 63\% carbohydrate and $23 \%$ protein, with total calorific value of $25 \mathrm{~kJ} / \mathrm{kg}$ ) or the experimental group $(n=50)$ which were fed a high-fat diet (high-fat chow comprising $32 \%$ fat, $48 \%$ carbohydrate and $20 \%$ protein, with total calorific value of $54.3 \mathrm{~kJ} / \mathrm{kg}$ ) and both groups animal received distilled water ad libitum. Once the rats reached a mean body weight of $300 \pm 20 \mathrm{~g}$, those in the experimental group were administered with $50 \mathrm{mg} / \mathrm{kg}$ streptozocin (STZ; cat. no. S0130; Sigma-Aldrich; Merck $\mathrm{KGaA}$; Darmstadt, Germany) dissolved in $0.01 \mathrm{mmol} / 1$ chilled citrate buffer ( $\mathrm{pH}$ 4.5) (cat. no. ZLI-9065; Beijing Zhongshan Golden Bridge Biotechnology Co., Ltd., Beijing, China) via intraperitoneal injection over a 30 -min period for 2 months. Control group rats were administered with same volume citrate buffer alone. Blood samples were subsequently collected from tail veins and used to determine glucose levels, as detailed below. A rat was considered a diabetic model once the fasting blood glucose concentration reached $16.7 \mathrm{mmol} / \mathrm{l}$ (Table I). A total of 20 rats in the experimental group did not develop diabetes; the 10 diabetic rats remainedwith the same high-sugar and high-fat diet for an additional week and were subsequently sacrificed. The liver, pancreas, kidney, and muscle tissue were carefully dissected from each ratfor immunohistochemical analysis.

For the in vivo nicotinamide mononucleotide (NMN) experiment, the diabetes induced rats (indicated above) were randomly divided into two groups (10 rats in each group): One group was administered $120 \mathrm{mg} / \mathrm{kg} \mathrm{NMN}$ (cat. no. N3501; Sigma-Aldrich, Merk KGaA; Darmstadt, Germany) in sterile PBS $(200 \mu \mathrm{l})$ subcutaneously in the loose skin around the neck and shoulder area every other day for 20 days, and another group (control group) was administered with $200 \mu 1$ sterile PBS via subcutaneous injection continuously every other day for 20 days. Following sacrifice, the animal kidney tissues were harvested to extract total RNA for reverse transcription-quantitative polymerase chain reaction.

A total of 5 insulin gene-mutant male C57/LB6 mice (10-11 weeks old; Michigan Diabetes Research and Training Center of the University of Michigan; Ann Arbor, MI, USA) (15) were spontaneously induced diabetic mice that served as a model for a subset of human insulin gene mutations that have been discovered to cause the autosomal-dominant syndrome, mutant insulin gene-induced diabetes, in younger persons (16). Wild-type C57/LB6 mice were used as a control group ( $n=5)$, which were purchased from the Michigan Diabetes Research and Training Center of the University of Michigan. Both groups of mice were maintained in an air-conditioned colony room (temperature, $21 \pm 1^{\circ} \mathrm{C}$; humidity, $50-60 \%$ ) on a natural light-dark cycle and received a normal diet with standard mice chow and water ad libitum. Housing conditions and experiments were approved by the Ethics Committee of Animal Experimentation of Guilin Medical University (Guilin, China). All mice were anesthetized using diethy ether inhalation and beheaded. Subsequently, kidney tissue was harvested for immunofluorescence and immune-focused detection for pathological tissue analysis. When all blood glucose levels in mice reached $>27.6 \mathrm{mmol} / 1$, this indicated the mice suffered from severe diabetes, and subsequently, the mice were sacrificed.

Cell culture experiments. The rat glomerular mesangial HBZY-1cell line was purchased from the Basic Medical Institute of the Chinese Academy of Medical Sciences (Beijing, China). Cells were maintained in Dulbecco's modified Eagle's medium (DMEM; Hyclone, Logan, UT, USA) containing 10\% fetal bovine serum (Gibco; Thermo Fisher Scientific, Inc., Waltham, MA, USA) at $37^{\circ} \mathrm{C}$. For in vitro assays, cells were cultured under normal glucose conditions $(5.6 \mathrm{mmol} / \mathrm{l})$ at $37^{\circ} \mathrm{C}$ for $24 \mathrm{~h}$, and subsequently subjected to high glucose ( $\mathrm{HG}$; $200 \mathrm{mmol} / \mathrm{l})$ as oxidative stress milieu $\left(5 \% \mathrm{CO}_{2}, 37^{\circ} \mathrm{C}\right)$ for 1-6 days, in which the medium was changed every other day. Furthermore, cells were grouped by incubation time (24-96-h groups), and were removed to detect the changes of oxidative stress and apoptosis in HG milieu. To determine the intervention of NMN at different time-points and doses, the cells were divided into four groups after 3 days of incubation at $37^{\circ} \mathrm{C}$ in $\mathrm{HG}$ milieu, and treated with $0,0.5,1$ or $2 \mathrm{mmol} / 1 \mathrm{NMN}$, respectively for a further $24 \mathrm{~h}$. Subsequently, the protein expression levels of Nampt, NF- $\kappa$ B p65, Sirt1, FoxO1 and Bax were measured using western blot analysis. 
Table I. Levels of blood glucose and insulin in diabetic rats.

\begin{tabular}{lccc}
\hline Group & $\mathrm{n}$ & $\begin{array}{c}\text { Blood glucose } \\
(\mathrm{mmol} / \mathrm{l})\end{array}$ & $\begin{array}{c}\text { Insulin } \\
(\mathrm{mU} / \mathrm{ml})\end{array}$ \\
\hline Control & 10 & $5.74 \pm 2.22$ & $24.91 \pm 1.23$ \\
Diabetes & 35 & $17.68 \pm 2.58^{\mathrm{a}}$ & $45.691 \pm 2.17^{\mathrm{b}}$ \\
\hline
\end{tabular}

The results indicate successful establishment of a model of type 2 diabetes mellitus. Data are presented as means \pm standard deviations of three experiments. ${ }^{\mathrm{a}} \mathrm{P}<0.05,{ }^{\mathrm{b}} \mathrm{P}<0.01$ vs. control.

In the same experimental conditions, the protein expression of Nampt, Sirt1, vimentin and fibronectin of the HBZY-1 cells were also detected by immunofluorescence techniques.

To further evaluate the effect of NMN, the following the experiment was measured and the cells were grouped into 7 groups after 3 days treated in HG milieu: i) normal glucose cultured (control group); ii) normal glucose $+10 \mu \mathrm{mol} / 1$ FK866 (Sigma-Aldrich; Merck KGaA); iii) normal glucose + $1 \mathrm{mmol} / 1$ NMN; iv) HG cultured (200 mmol/1 HG; HG control group); v) $\mathrm{HG}+10 \mu \mathrm{mol} / 1 \mathrm{FK} 866$; vi) $\mathrm{HG}+1 \mathrm{mmol} / 1 \mathrm{NMN}$; and vii) $\mathrm{HG}+10 \mu \mathrm{mol} / 1 \mathrm{FK} 866+1 \mathrm{mmol} / 1 \mathrm{NMN}$. FK866 and NMN were added into the cells at $24 \mathrm{~h}$ prior to cell harvesting. The protein expression of Nampt, vimentin and fibronectin were detected by western blot analysis. Once the cells were cultured with HG for 4 days, $10 \mu \mathrm{mol} / 1$ FK866 and $1 \mathrm{mmol} / 1 \mathrm{NMN}$ were added (in accordance with the previous NMN dose-effect) and the protein expression levels of Nampt, Sirt1 and NF- $\kappa$ B p65 were also analyzed using western blot analysis.

Blood glucose and insulin detection. Collected from rat tails in regular intervalsonce every 3 days for one week, blood glucose levels were measured using commercially available colorimetric diagnostic kits (GT-1640; Omron Corp., Kyoto, Japan) according to the manufacturer's instructions. The blood samples intended for serum insulin testing were collected as described in in the instructions of Iodine $\left[{ }^{125} \mathrm{I}\right]$ Insulin Radio immuno assay $\mathrm{k}^{*}$-it (Beijing Research Institute of Biotechnology of the North, Beijing, China). Serum insulin levels were measured using a FJ-2008PS Gamma Immune Counter (Beijing North Biotechnology Research Institute, Beijing, China).

Immunohistochemistry and immunofluorescence assay. The HBZY-1 A cells cultured on the slide were fixed with $4 \%$ paraformaldehyde at room temperature for $20 \mathrm{~min}$, permeabilized with $0.5 \%$ Triton X-100 for 15 min, and blocked with $2 \%$ bovine serum albumin (Gibco; Thermo Fisher Scientific, Inc.) for $1 \mathrm{~h}$ at room temperature. Nampt, vimentin, fibronectin, nuclear factor $(\mathrm{NF})-\kappa \mathrm{B}$ p 65 and sirtuin 1 (Sirt1) proteins were detected via incubation for $1 \mathrm{~h}$ at room temperature with antibodies of Nampt (1:100 dilution; sc-166866), vimentin (1:100 dilution; sc-32322), fibronectin (1:100 dilution; sc-52331; Santa Cruz Biotechnology, Inc., Dallas, TX, USA), NF-кB p65 (1:500 dilution; ab16502) and Sirt1 (1:1,000 dilution; ab7343) (Abcam, Cambridge, UK) were usedat $4^{\circ} \mathrm{C}$ overnight. Subsequently, blots were incubated at room temperature for
$1 \mathrm{~h}$ and in the dark with Alexa Fluor 488-conjugated (1:500 dilution; A32723) or Alexa Fluor 594-conjugated (1:1,000 dilution; A-11007) second antibody (Molecular Probes; Thermo Fisher Scientific, Inc., Waltham, MA, USA) and diluted in 2\% normal goat serum, $1 \%$ bovine serum albumin and $0.1 \%$ Triton $\mathrm{X}-100$ in PBS. The cells nuclei stained with $5-\mu \mathrm{mol} / 1$ DAPI nuclear stain (Thermo Fisher Scientific, Inc.) for $1 \mathrm{~h}$ at room temperature. Stained slides were mounted and imaged using a Fluoview 500 confocal microscope (Olympus Corporation, Tokyo, Japan).

Immunohistochemical analysis was performed on rat tissues that were fixed in $4 \%$ paraformaldehyde (Sigma-Aldrich; Merck KGaA) at room temperature for $5 \mathrm{~min}$, dehydrated in ascending grades of alcohols, cleared in xylene, embedded in paraffin and cut into $4 \mu \mathrm{m}$-thick on the slide. Sections were dewaxed with dimethylbenzene, rehydrated with gradient alcohol and permeablized with $1 \mathrm{X}$ citric acid solutionfor 2-3 min. Sections were incubated overnight with a primary antibody against Nampt (1:300 dilution; sc-373717; Santa Cruz Biotechnology, Inc.) in a humidified chamber at $4^{\circ} \mathrm{C}$. A horseradish peroxidase-labeled sheep anti-rabbit secondary at room temperature for $1 \mathrm{~h}(31460 ; 1: 200$ dilution; Thermo Fisher Scientific, Inc.) was subsequently added to the sections at room temperature for $20 \mathrm{~min}$. For coloration, slides were incubated with a solution of $0.05 \%$ 3,3'-diaminobenzidine at $37^{\circ} \mathrm{C}$ for 10 minand $0.01 \% \mathrm{H}_{2} \mathrm{O}_{2}$, using a DAB chromogenic reagent kit (3PW017; Sangon Biotech Co., Ltd., Shanghai, China). Subsequently, brown staining, which indicated immune response strength of Nampt in the tissue sections, was analyzed using an Image-Pro Plus Version 6.0 color image analysis system (Media Cybernetics, Inc., Rockville, MD, USA). The degree of positive staining was determined from the mean value of 10 different fields per slide and proportions of positive cells were scored as follows: 0 , no positive cells; $1,<10 \% ; 2,11-50 \% ; 3,51-75 \%$; and $4,>75 \%$. The degree of positivity was scored as follows: 0, no staining (i.e., consistent with the background color); 1, light yellow (slightly higher than the background); 2, tan (significantly higher than the background); and 3, brown. The values were multiplied to yield total scores, which were classified as follows: 0-2, negative (-); 3-4, weakly positive (+); 5-8, moderately positive $(++)$; and 9-12 strongly positive (+++) as described previously (17).

For immunofluorescence, mice kidney tissues were cut into $3-\mu \mathrm{m}$ thick paraffin-embedded sections on glass slides were prepared, dewaxed, and rehydrated. The sections were permeabilized in $0.1 \%$ Triton X-100 at room temperature for $20 \mathrm{~min}$. Subsequently, the slides were blocked in $5 \%$ donkey serum $37^{\circ} \mathrm{C}$ for 10 min (3AS10 1563; Agrisera, Los Angeles, USA) in PBS and then incubated at $4{ }^{\circ} \mathrm{C}$ overnight with anti-mouse primary antibodies Nampt (1:50; BS6044), vimentin (1:100; BS1491) and fibronectin (1:100; BS4646; all Bioworld Technology, Inc., St. Louis Park, MN, USA). Samples were then incubated with Alexa Fluor 594-conjugated (1:1,000; R37121) and Alexa Fluor488-conjugated (1:250; A-21121; both Thermo Fisher Scientific, Inc.) secondary antibodies at room temperature for $1 \mathrm{~h}$ and maintained in a dark place. Cell nuclei were stained with 5- $\mu \mathrm{mol} / 1$ 4',6-diamidino-2-phenylindole (D1306; Thermo Fisher Scientific, Inc.) at room temperature for $5 \mathrm{~min}$. Stained slides were mounted and imaged (magnification, x64) using a Fluoview 500 confocal microscope (Olympus Corporation). 
Immunofluorescence signals were quantified using Image $\mathbf{J}$ version 2 software (National Institutes of Health, Bethesda, MD, USA), as described by Yu et al (17), and the integrated densities of immune fluorescence positive signals were measured.

$N A D / N A D H$ assay. For NAD/NADH assays of rat tissues, $30 \mathrm{mg}$ frozen muscle, pancreas, liver, kidney or an erythrocyte cell pellet (30 $\mu \mathrm{l}$ packed erythrocytes/ml Earle's balanced salt solution (Thermo Fisher Scientific, Inc.) subjected to 4-h incubation at $37^{\circ} \mathrm{C}$ in $10 \mu \mathrm{mol} / 1 \mathrm{~N} 1-m e t h y l n i c o t i n a m i d e$ (AG-D-34551; Angene International Ltd., Nanjing, China) and subsequent centrifugation at $1,500 \mathrm{x} \mathrm{g}$ and $4^{\circ} \mathrm{C}$ for $10 \mathrm{~min}$ ) were each homogenized in $400 \mu 1 \mathrm{NAD} / \mathrm{NADH}$ Extraction Buffer (BioVision, Inc., Milpitas, CA, USA), followed lysates incubated at room temperature for $5 \mathrm{~min}$ and subjected to ultrafiltration through 10-kD cut-off filters (BioVision, Inc.). The lysates were further subjected to analysis using NAD/NADH quantification kits (K337-100; BioVision, Inc.) according to the manufacturer's instructions.

Reverse transcription-quantitative polymerase chain reaction $(R T-q P C R)$. Total RNA was extracted from the kidney tissues using TRIzol reagent (Invitrogen; Thermo Fisher Scientific, Inc.) according to the manufacturer's protocol. The sequences of the primers used were as follows: Nampt (109 bp), forward 5'-ATAGGGGCATCTGCTCATTT-3' and reverse, 5'-ACTGTGCTCTGCCGCTGGAA-3'; NF- $\kappa$ B p65 (221 bp) forward, 5'-GACCTGGCATCTGTGGACAAC-3' and reverse, 5'-TCCGCAATGGAGGAGAAGTCT-3'; Sirt1 (506 bp), forward, 5'-GGATCCTTCATTTATCAGAGTTGC CACC-3' and reverse, 5'-CTTCGAGGTTCTTCTAAACTT GGACTCTGG-3'; vimentin (50 bp) forward, 5'-ATGAAA GTGTGGCTGCCAAGAAC-3' and reverse, 5'-GTGACT GCACCTGTCTCCGGTA-3'; and $\beta$-actin (30 bp) forward, 5'-GATGGTGGGTATGGGTCAGAAGGAC-3' and reverse, 5'-GCTCATTGCCGATAGTGATGACCT-3'. All primers were synthesized by Shanghai Sangon Biological Engineering Technology \& Services Co., Ltd., (Shanghai, China). For the reverse transcription template, in a $0.5-\mathrm{ml}$ tube, $1 \mu \mathrm{l}$ Thermo Script RT, $1 \mu$ l Oligo $(\mathrm{dT})_{20}, 2 \mu \mathrm{l}$ of $50 \mathrm{ng} / \mu \mathrm{l}$ random primer, $4 \mu \mathrm{ldNTP}$ mix, $1 \mu \mathrm{l} 40 \mathrm{U}$ RNaseOUT, $10 \mu \mathrm{l}$ of $0.1 \mathrm{M}$ DTT, $2 \mu \mathrm{l}$ E. coli RNase and $20 \mu \mathrm{l}$ XX cDNase Synthesis Buffer were added and adjusted to a final volume volume $50 \mu \mathrm{l}$ with DEPC-treated water. RT reaction included was performed at $56^{\circ} \mathrm{C}$ for $1 \mathrm{~h}$ before the addition of $1 \mu \mathrm{l}$ Rase $\mathrm{H}$. The reaction was incubated at $37^{\circ} \mathrm{C}$ for $20 \mathrm{~min}$ and $2 \mu \mathrm{l}$ aliquot was removed for PCR. qPCR was performed with $1 \mu \mathrm{l}$ cDNA, using an RT-PCR kit (K1691; Thermo Fisher Scientific, Inc.) according to the manufacturer's instructions. The reaction conditions included denaturation at $94^{\circ} \mathrm{C}$ for $2 \mathrm{~min}$, renaturation at $58^{\circ} \mathrm{C}$ for $50 \mathrm{sec}$ and extension at $72^{\circ} \mathrm{C}$ for $30 \mathrm{sec}$, with 30 cycles in total. The collected amplification products were separated via $2 \%$ agarose gel electrophoresis and visualized by ethidium bromide staining. Band intensity analysis was performed with Gene Tools software (UVP, Inc., Upland, CA, USA). All RT-PCR procedures were performed using a Thermo Script RT-PCR System (Thermo Fisher Scientific, Inc.).

Western blot analysis. Total proteins from HBZY-1 cells and from rat tissues (liver, pancreas, muscle and kidney)
Table II. Endogenous Nampt expression in diabetic rat tissue samples.

\begin{tabular}{lccccc}
\hline Group & $\mathrm{n}$ & Liver & Pancreas & Muscle & Kidney \\
\hline Control & 10 & ++ & + & + & ++ \\
Diabetes & 35 & +++ & ++ & +++ & +++ \\
\hline
\end{tabular}

Data are presented as means \pm standard deviations of three experiments. Three nephritic sections were taken from each of 3 mice per group. In each nephritic section, $\geq 10$ areas containing $\sim 100$ cells were analyzed.

were extracted using a Protein Extraction Kit (Kangchen Biotechnology, Shanghai, China) according to the manufacturer's protocol. Protein quantification was performed using a BCA protein concentration determination kit (23235; Leagene Biotechnology Ltd., Beijing, China) according to the manufacturer's instructions. The protein $(30 \mu \mathrm{g})$ was loaded and separated using 10\% SDS-PAGE, and subsequently transferred onto a polyvinylide fluoride sheets membranes (Thermo Fisher Scientific, Inc.). The membranes were blocked in 5\% skimmed milk dissolved in tris-buffered saline with Tween-20 (TBST) at room temperature for $1 \mathrm{~h}$. The membranes were incubated with rabbit polyclonal antibodies against Nampt (1:200 dilution; sc-166866), Poly(ADP-ribose) polymerase-1 (PARP-1; 1:500 dilution; sc-136208), Sirt1 (1:500 dilution, sc-74465), vimentin (1:200 dilution; sc-166866), fibronectin (1:200 dilution; sc-69681), forkhead box protein O1 (FoxO1; 1:500 dilution; sc-374427), NF-кB p65 (1:200 dilution; ab-86299) and B-cell lymphoma 2-like protein 4 (Bax; 1:400 dilution; sc-20067; Santa Cruz Biotechnology, Inc.) and a rabbit monoclonal antibody against $\beta$-actin (1:200 dilution; TA310155; OriGene Technologies, Inc., Beijing, China) overnight at $4^{\circ} \mathrm{C}$. Subsequently, following incubation with horseradish peroxidase-conjugated goat anti-rabbit (1:2,000 dilution; 170-6515; Bio-Rad, Hercules, CA, USA) and goat anti-rat IgG H\&L (1:2,000 dilution; ab97057; Abcam, Cambridge, UK) secondary antibodies at $37^{\circ} \mathrm{C}$ for $1 \mathrm{~h}$, blots were developed using an enhanced chemiluminescence substrate according to the manufacturer's protocol (GE Healthcare, Chicago, IL, USA). Gray-scale (total raw density) values of blots were measured using the VisionWorksLS analysis software provided with the UVP EC3 (600) Imaging System (Quantity One; Bio-Rad Laboratories, Inc., Hercules, CA, USA).

Statistical analysis. Statistical analyses were performed using SPSS 16.0 package (SPSS, Inc., Chicago, IL, USA). A one-way analysis of variance was used for the analyses, and data are presented as the mean \pm standard error of the mean. $\mathrm{P}<0.05$ was considered to indicate a statistically significant difference.

\section{Results}

Upregulation of endogenous Nampt and PARPI in STZ-induced diabetic mice. Endogenous Nampt expression in rat tissues were presented (Figs. 1 and 2; Table II) via immunohistochemistry and western blot techniques. Expression levels of endogenous Nampt in the liver, pancreas, muscles, and kidney in diabetic 
A

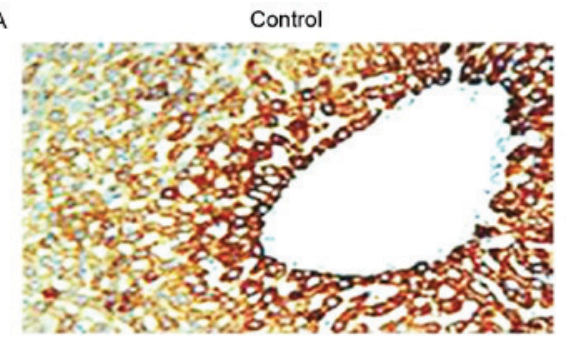

B

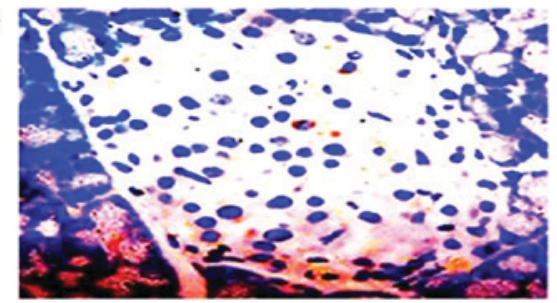

C


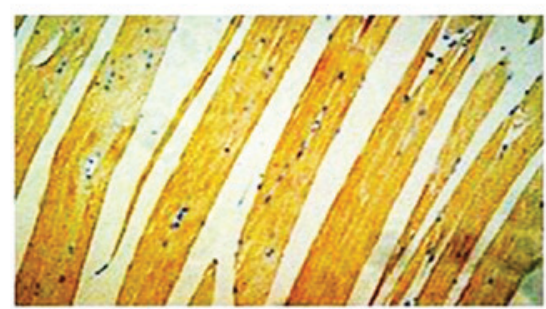

Diabetic tissues
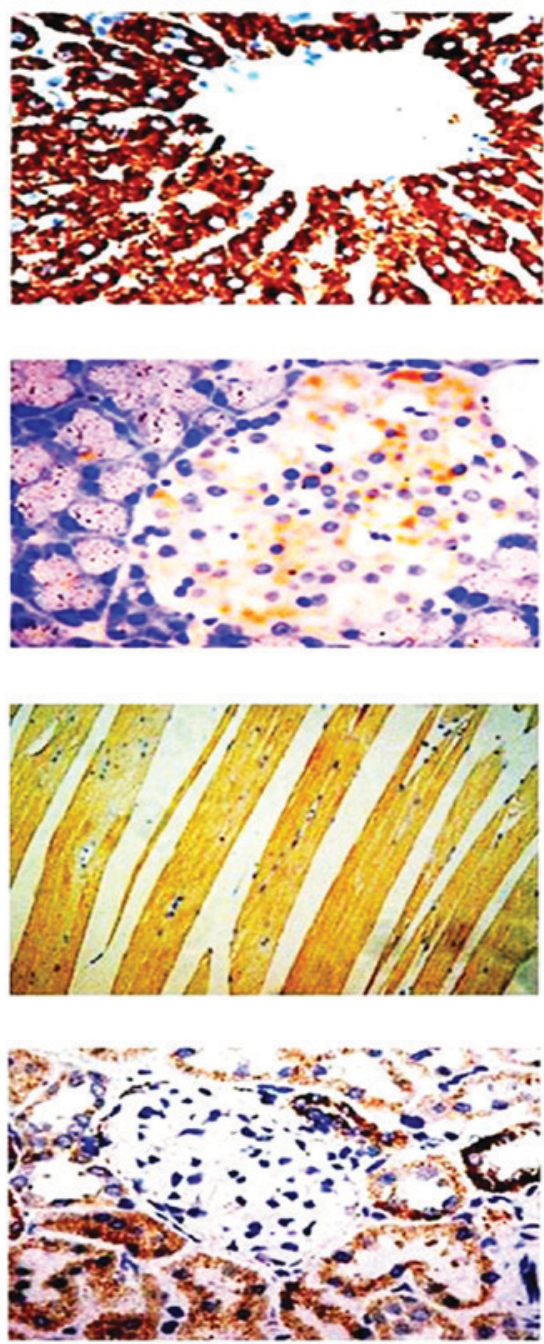

Figure 1. Endogenous Nampt upregulation in streptozocin-induced diabetic Sprague-Dawley rats. Endogenous Nampt expression and localization in the (A) liver, (B) islets, (C) muscles and (D) kidney tissues of normal and diabetic rat tissues were assessed using immunohistochemistry. Nampt expression levelsin cells is indicated by palm red. Nampt, nicotinamide phosphoribosyltransferase. Magnification, $\mathrm{x} 40, \mathrm{Scale}$ bar=100 $\mu \mathrm{m}$.
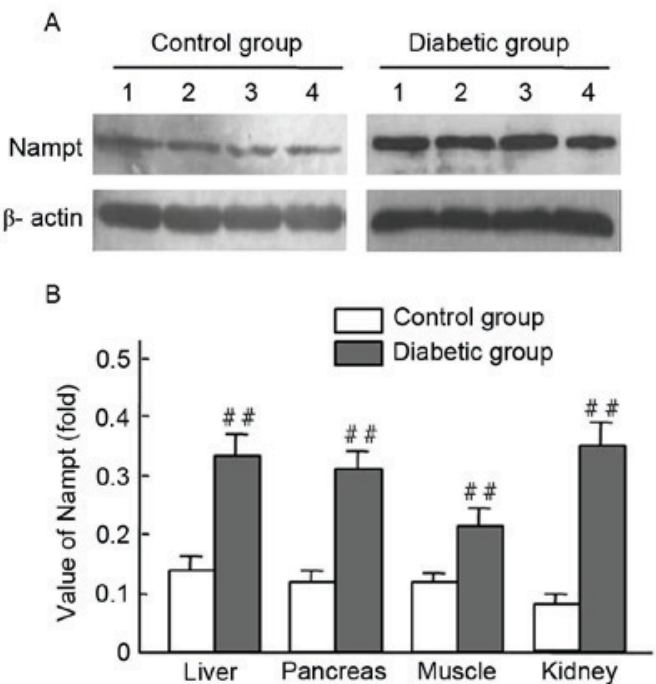
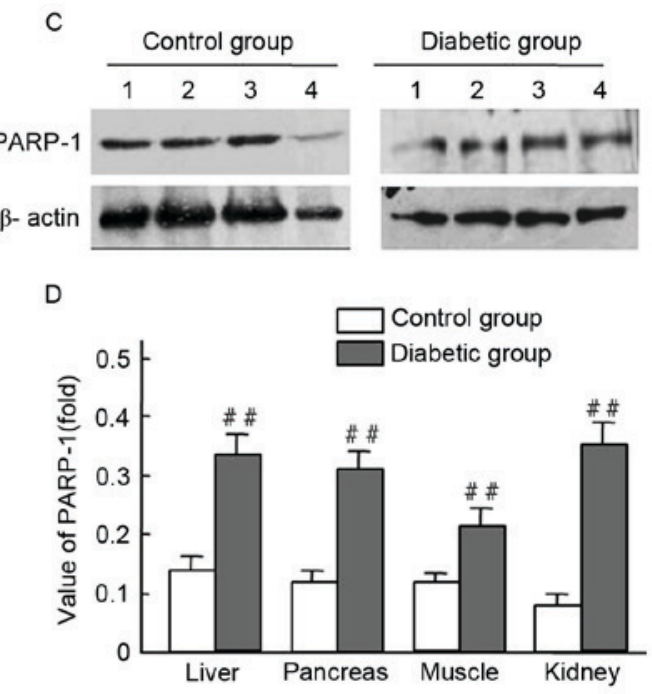

Figure 2. Nampt and PARP-1 expression levels in tissues from streptozocin-induced diabetic and normal rats. Rat tissue lysates were subjected to western blot analysis with antibodies against Nampt, PARP-1 and $\beta$-actin (control); experiments were performed at least in duplicate. Representative images of bands are shown. Data are presented as means \pm standard deviations for 3 pancreatic sections from 3 rats per group. (A-D) The expression levels of Nampt and PARP-1 were obiviously increased in the diabetic liver, pancreas, musle and kidney tissues compared with those of normal rats, ${ }^{\# \#} \mathrm{P}<0.01 \mathrm{vs.} \mathrm{control}$. Nampt, nicotinamide phosphoribosyltransferase; PARP-1, Poly(ADP-ribose) polymerase-1; band 1, liver; band 2, pancreas; band 3, muscle; band 4, kidney. 
rats were all higher than those of the control group; respective increases of 3.22-, 2.54-, 2.73-, and 2.36-fold were observed (Fig. 2A and B). Furthermore, PARP-1 expression levels in the liver, pancreas, muscles, and kidney of diabetic rats were higher than those of the control group; respective increases of 2.47-, 2.57-, 1.60- and 3.63-fold were observed (Fig. 2C and D). Significant increases of endogenous Nampt and PARP-1 expression were observed in tissues from diabetic rats, compared with controls ( $\mathrm{P}<0.01$; Fig. 2B and $\mathrm{D})$.

Dysregulated NAD and NADH levels in STZ-induced diabetic rats. Diabetes is known to be associated with oxidative stress (18). It was therefore examined whether oxidative stress was an etiological factor in diabetic rats. Initially, changes of NAD, NADH and the NAD/NADH ratio in rat tissues were evaluated. Notably, a significant increase in NADH levels were observed in the erythrocytes, muscle, pancreas, liver and kidney of diabetic rats, whereas NAD levels were significantly decreased compared with the control group $(\mathrm{P}<0.01$; Fig. 3). All values of NAD/NADH ratio were significantly reduced in the tissue from diabetic rats compared with controls $(\mathrm{P}<0.01$; Fig. $3 \mathrm{~A}-\mathrm{E})$. The results indicate that STZ-induced diabetes in SD rats may induce an imbalance in the NAD/NADH ratio under oxidative stress.

Increased Nampt and $N F-\kappa B$ p65 expression and decreased Sirtl expression in response to $H G$ conditions over time. The expression levels of endogenous Nampt, NF- $\kappa$ B p65, and Sirt1 were measured in HBZY-1 cells treated continuously in an HG milieu for 24, 48, 72, 96, 120, and $144 \mathrm{~h}$ (Fig. 4). The western blot results indicated endogenous Nampt and NF- $\mathrm{B}$ p65 expression levels were increased in a time-dependent manner (Fig. 4A), and 72-144-h incubation resulted in a significant increase in expression compared with 24 -h incubation $(\mathrm{P}<0.05$ and $\mathrm{P}<0.01$; Fig. 4B and D). Furthermore, Sirt1 expression was significantly decreased when the cells were cultured in HG milieu for 72-120 h compared with 24-h incubation $(\mathrm{P}<0.05$ and $\mathrm{P}<0.01$; Fig. $4 \mathrm{C}$ ). These results suggest that Nampt upregulation may affect the expression of $\mathrm{NF}-\kappa \mathrm{B}$ p65 and Sirtl following exposure of cells to HG milieu.

To further investigate this, HBZY-1 cells were exposed to $\mathrm{HG}$ for a further $120 \mathrm{~h}$ prior to immunofluorescence analysis. Nampt upregulation was indicated under fluorescence microscopy as increased green flurorescence was observed in the HG milieu group compared with the control. Further staining revealed a notable increase in $\mathrm{NF}-\kappa \mathrm{B}$ p 65 expression in $\mathrm{HG}$ cells and translocation from the cytosolinto the nuclei, compared with controls (Fig. 5A). Quantification of the images revealed that the increase in $\mathrm{NF}-\kappa \mathrm{B}$ p65 was statistically significant $(\mathrm{P}<0.01$; Fig. 5B). Similarly, Nampt expression was significantly increased $(\mathrm{P}<0.01$; Fig. $5 \mathrm{~B})$. Conversely, in HG cells, Sirtl expression was decreased compared with the 24-h control group; however, Nampt expression was increased (Fig. 5C). Quantification of these results indicated these differences were statistically significant $(\mathrm{P}<0.01$; Fig. 5D).

Induction of cell apoptosis by HG-mediated oxidative stress. To further confirm the upregulation of endogenous Nampt following exposure to oxidative stress milieu, cells were incubated in HG DMEM medium for 24-96 h. Subsequently, relative protein expression levels of Nampt, NF- $\kappa$ B p65, Sirt1, FoxO1 and Bax at
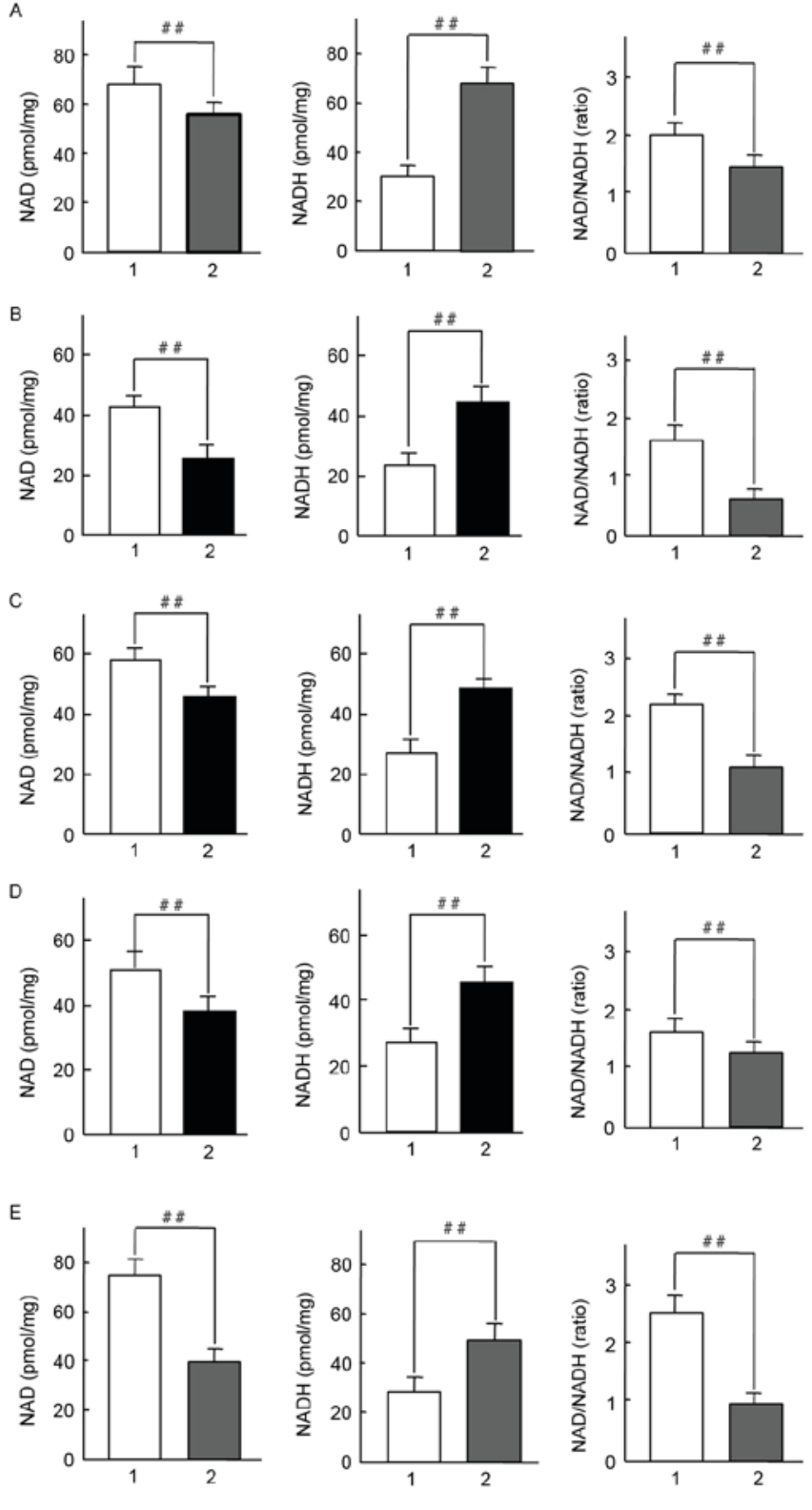

1. Normal rat tissue

2. Diabetic rat tissue

Figure 3. Changes in NAD and NADH levels in tissues from diabetic Sprague-Dawley rats. NAD/NADH ratios were measured in (A) erythrocytes, (B) muscle, (C) pancreatic, (D) liver and (E) kidney tissues. A total of 4 tissue samples were assessed in same concentration of total protein. Data are presented as means \pm standard deviations of 3 rats per group. ${ }^{\# \#} \mathrm{P}<0.01$ vs. normal rat tissues. NAD, nicotinamide adenine dinucleotide.

different time points were measured by western blotting (Fig. 6). A representative image of the western blot results is indicated in Fig. 6A. Endogenous Nampt expression significantly increased by $96 \mathrm{~h}$ to 3.47 times that at $24 \mathrm{~h}$ (Fig. 6B). Furthermore, NF- $\kappa \mathrm{B}$ p65, FoxO1 and Bax expression subsequently increased to varying degrees following Nampt upregulation. Protein expression levels of Nampt, FoxO1 and Bax peaked at $96 \mathrm{~h}$, whereasNF- $\kappa$ B p65 peaked at $72 \mathrm{~h}$ (Fig. 6C, D and F). As indicated in Fig. 6E, Sirtl expression was significantly decreased following $96 \mathrm{~h}$ exposure to a HG milieu $(\mathrm{P}<0.01)$.

Upregulation of Nampt is closely associated with renal fibrosis in diabetic mice. It was investigated whether Nampt 
A

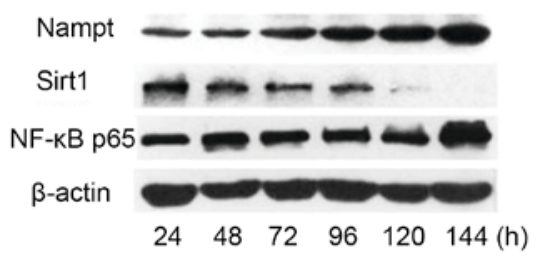

C

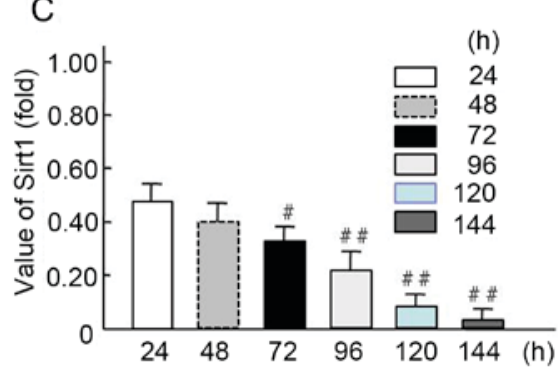

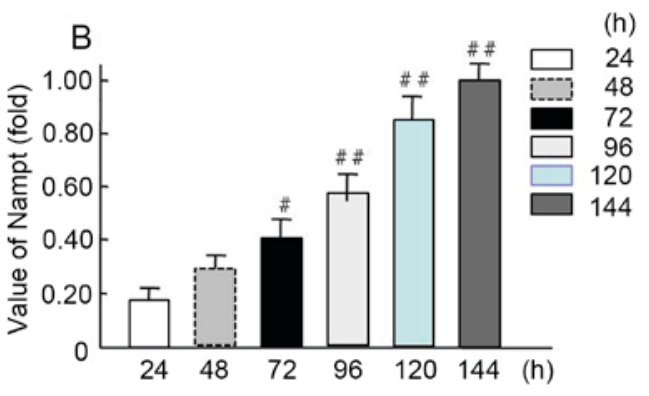

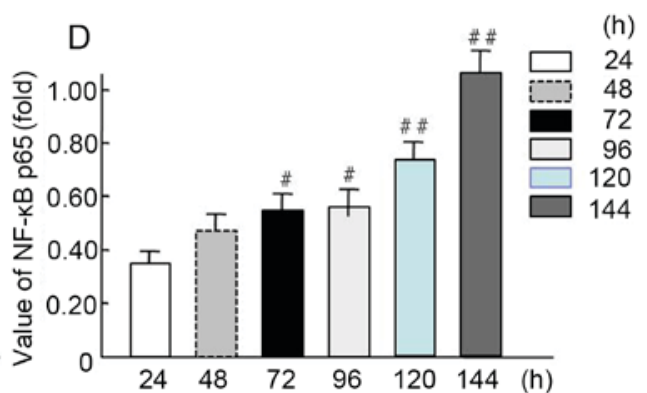

Figure 4. Increased endogenous Nampt and NF-kB p65 expression and decreased Sirt1 expression in oxidative stress-impaired HBZY-1 cells. (A) HBZY-1 cells were incubated in a high glucose media ( $200 \mathrm{mmol} / \mathrm{l}$ as oxidative stress milieu) for $24,48,72,96,120$, or $144 \mathrm{~h}$, then the expression levels of endogenous

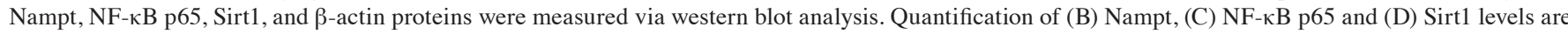
presented. Each independent experiment was repeated three times per group. Data are presented as means \pm standard deviations of three experiments. ${ }^{\sharp} \mathrm{P}<0.05$, ${ }^{\# \#} \mathrm{P}<0.01$ vs. 24-h treated group. Nampt, nicotinamide phosphoribosyltransferase; Sirt1, sirtuin 1; NF, nuclear factor.
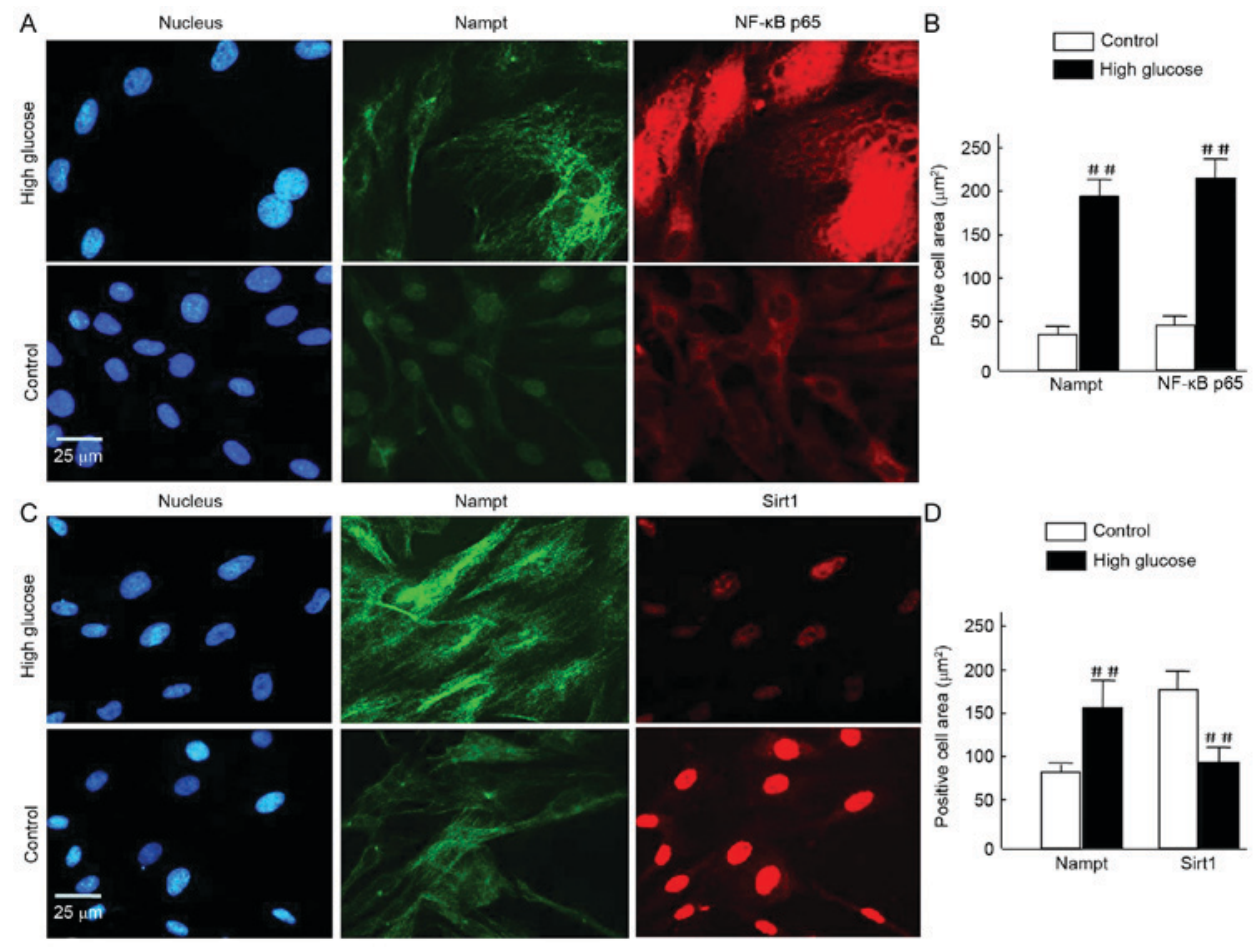

Figure 5. (A-D) To assess cell morphology using fluorescence microscopy, HBZY-1 cells were exposed tohigh glucose for $120 \mathrm{~h}$ and subsequently fixed and stained with Alexa Fluor 488- and Alexa Fluor 594-conjugated rabbit antibodies against Nampt, NF-кB p65, and Sirt1, and DAPI (blue) for nuclear visualization. Similar results were obtained in 3 independent experiments. (A and C) In the images, Nampt staining is indicated in green, and NF- $\mathrm{B}$ p65 or Sirt1 staining is indicated in red. Merged images reveal that the majority of Nampt staining co-localizes with both NF- $\mathrm{KB}$ p65 and Sirt1. (B and D) Positive signals were normalized to the cell area (integrated density $/ \mathrm{mm}^{2}$ ) and quantitatively analyzed using Image $\mathbf{J}$ software. In each nephritic section, $\geq 10$ areas containing $\sim 100$ cells were analyzed. Data are expressed as means \pm standard deviations of four independent experiments ( $\sim 50$ cells per experiment). Magnification, $\mathrm{x} 40$, Scale bar $=25 \mu \mathrm{m} .{ }^{\# \#} \mathrm{P}<0.01$ vs. control. Nampt, nicotinamide phosphoribosyltransferase; NF, nuclear factor; Sirt1, sirtuin 1.

upregulation was able to induce the expression of renal cell fibrotic factors, such as vimentin and fibronectin, in an insulin gene-mutant diabetic C57/LB6 mouse model. With double immunofluorescence staining, glomerularmorphology and distribution, and localization of target proteins in kidney sections were detected viaconfocal microscopy (Fig. 7). The 
A

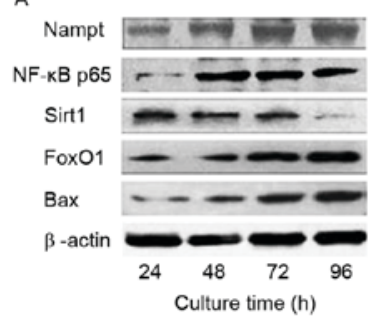

D

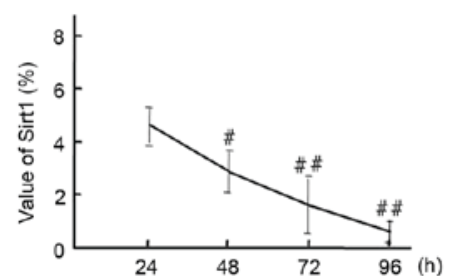

B



E

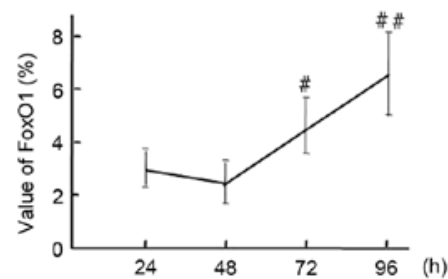

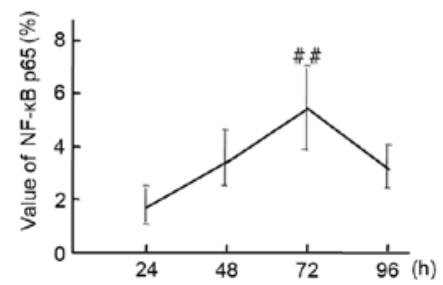

$F$

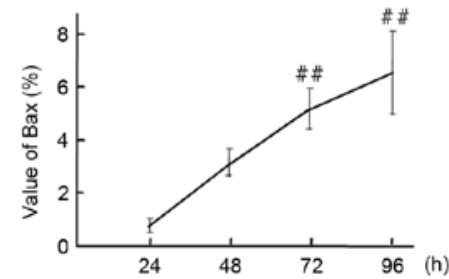

Figure 6. (A) Time course of endogenous Nampt, NF-кB p65, Sirt1, FoxO1, and Bax protein expression in HBZY-1 cells exposed to a high-glucose milieu for 24, 48, 72, or $96 \mathrm{~h}$. Quantification of western blot analysis indicated the protein expression levels of (B) Nampt, (C) NF-kB p65, (D) Sirt1, (E) FoxO1 and (F) Bax, and $\beta$-actin were indicated. Data are presented as means \pm standard deviations of three experiments. ${ }^{\# P}<0.05$, ${ }^{\# \#} \mathrm{P}<0.01 \mathrm{vs} .24 \mathrm{~h}$ (control). Nampt, nicotinamide phosphoribosyltransferase; NF, nuclear factor; Sirt1, sirtuin 1; FoxO1, forkhead box protein O1; Bax, B-cell lymphoma 2 -like protein 4.

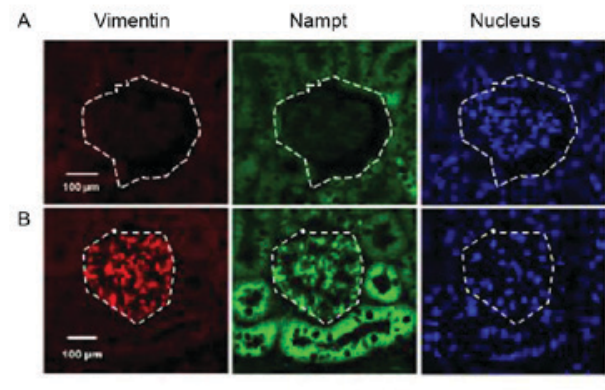

E

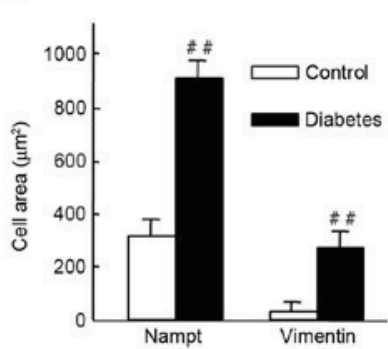

Merge
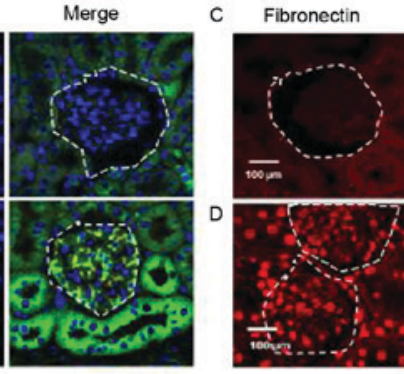

Nampt

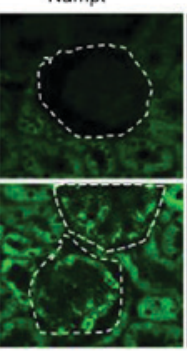

Nucleus


Figure 7. Endogenous Nampt, vimentin, and fibronectin expression in nephritic tissues of diabetic mice. The inner circle of the broken line indicated the glomerulus cells, which were surrounded by renal tubular cells. (A-D) Representative images of double immunestaining for Nampt (green) and fibronectin or vimentin (red). Nuclei were stained with DAPI (blue). Magnification, x64, Scale bar=100 $\mu$ m. (E) Endogenous Nampt and vimentin expression levels were significantly higher in nephritic tissue cells from diabetic micethan in cells from control mice. (F) Similarly, fibronectin levels were significantly higher in tissues from diabetic mice than from control mice. Images were analyzed using Image J software. Data are presented as means \pm standard deviations for 3 mice per group and 3 nephritic sections per mouse. In each nephritic section, $\geq 10$ areas containing $\sim 100$ cells were analyzed. ${ }^{\#} \mathrm{P}<0.01$ vs. controls. Magnification, x64, Scale bar $=100 \mu \mathrm{m}$. Nampt, nicotinamide phosphoribosyltransferase.

findings revealedsevere glomerular atrophy and size reductions in sections of diabetic mice kidney. Following Nampt upregulation in renal tubular and glomerular tissue, increased vimentin expression was observed specifically in glomerular cells but not in renal tubular cells (Fig. 7A and B). Notably, Nampt and vimentin expression levels were significantly higher in diabetic sections compared with control sections $(\mathrm{P}<0.01$; Fig. 7E). Fibronectin expression was increased in diabetic glomerular cells compared with controls ( $\mathrm{P}<0.01$; Fig. 7C, D and F). Similar results were also observed in HBZY-1 cells when subjected to
HG-mediated oxidative stress $(\mathrm{P}<0.01$; Fig. 8). These results suggested that there may be an association between Nampt and fibrotic factors, such as vimentin and fibronectin.

NMN regulates kidney cell fibrosis by Nampt-NF- $\kappa B$ p 65 and Sirtl signaling pathway in vivo and in vitro. The mRNA expression of Nampt, NF- $\mathrm{B}$ p65 and vimentin were significantly decreased in the NMN treated group compared with the untreated group $(\mathrm{P}<0.01)$, whereas expression of Sirt1 was significantly increased in the same group $(\mathrm{P}<0.01)$. These 

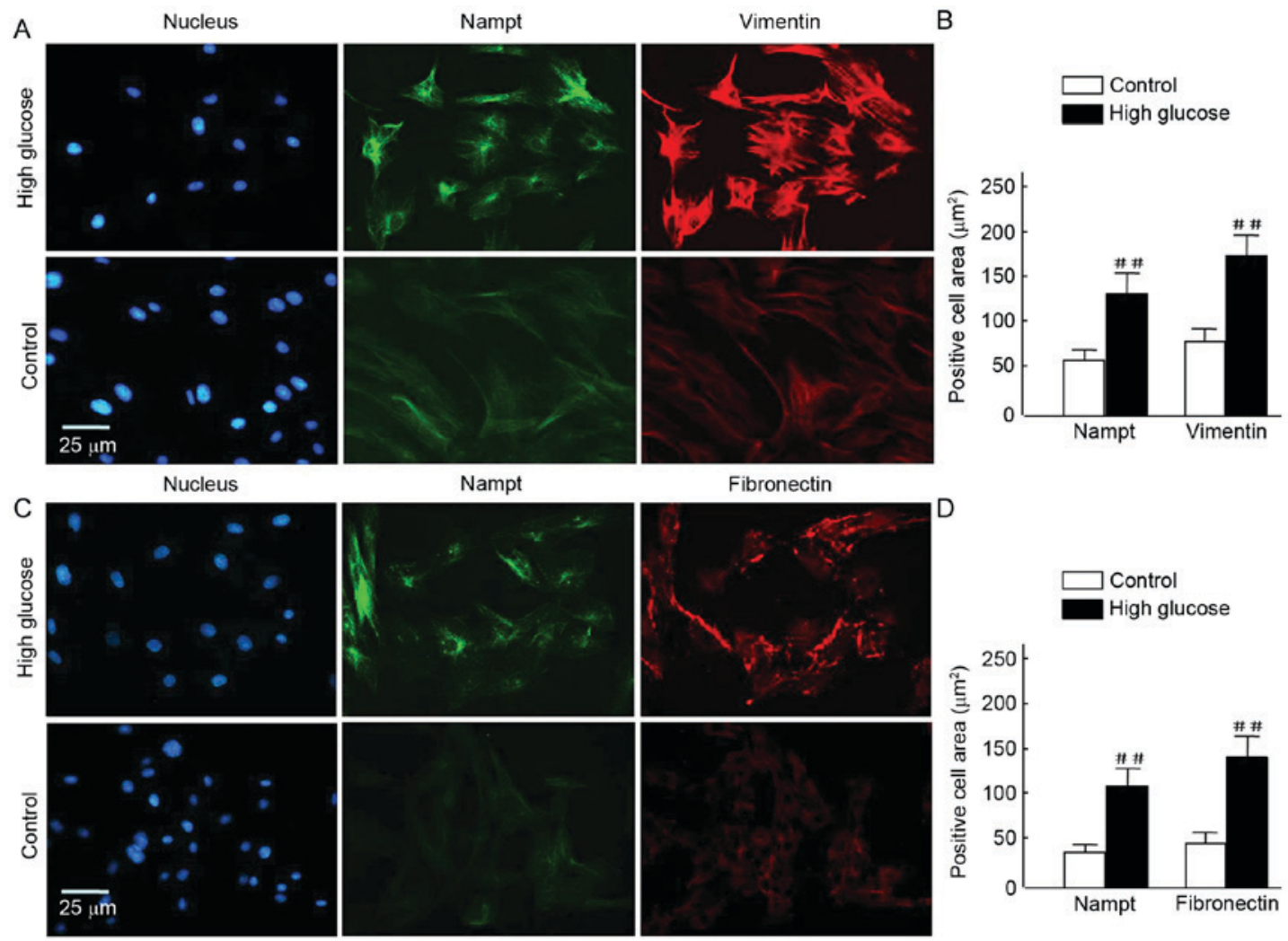

Figure 8. (A-D) Vimentin and fibronectin overexpression following endogenous Nampt upregulation in cells exposed to high-glucose. Endogenous Nampt, vimentin, and fibronectin expression levels were evaluated via immunofluorescent staining following a 72-h exposure to high-glucose conditions. (A and C) Representative images of double immunostaining for Nampt (green) and vimentin or fibronectin (red) are shown. Nuclei were stained with DAPI (blue). Magnification, $\mathrm{x} 40$, Scale bar $=25 \mu \mathrm{m}$. (B and D) All images were analyzed using Image $\mathrm{J}$ software. Data are presented as means \pm standard deviations of three experiments. ${ }^{\# \#} \mathrm{P}<0.01$ vs. control. Nampt, nicotinamide phosphoribosyltransferase.

results suggest that the Nampt-NF- $\mathrm{B}$ p65 signal pathway was specifically inhibited by NMN via a negative feedback loop (Fig. 9). To determine whether the Nampt-NF-kB p65 and Sirtl signaling pathway has a role in vimentin expression, the expression levels of Sirtl were measured in time- and dose-mediated manners in HG-cultured HBZY-1 cells by intervention of exogenous NMN (Fig. 10). The results indicated that NMN was able to activate Sirt1 by inhibiting the Nampt pathway. Following NMN treatment, the expression of Sirt1 was significantly increased compared with the NMN-untreated group. $(\mathrm{P}<0.01$; Fig. $10 \mathrm{~A})$, which may induce the downregulation of vimentin expression via interacting withNF-kB p65. Furthermore, results indicated that Sirt1 expression was significantly increased in all NMN-treated groups compared with NMN-untreated group ( $\mathrm{P}<0.01$; Fig. 10B). The result suggested that exogenous NMN may protect cells from fibrosis by inhibiting Nampt upregulation and promoting Sirt1 expression, but restraining NF-кB p65.

Vimentin and Fibronectin expression levels were downregulated in response to FK866 and NMN treatment. Western blot analysis was used to investigate the mechanisms underlying Vimentin and Fibronectin over expression, following the hypothesis that endogenous Nampt may affect NF-кBp65 pathway activation (Fig. 11). A representative western blot is presented in Fig. 11A. Notably, Vimentin and Fibronectin were significantly decreased in NMN-treated cells compared
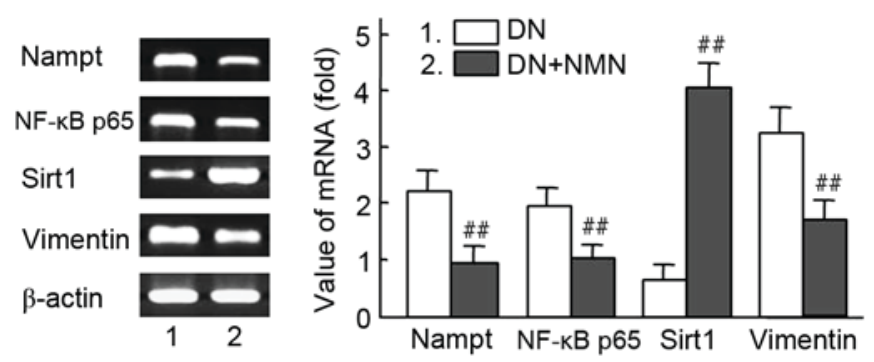

Figure 9. Effect of NMN on RNA expression of Nampt, NF- $\mathrm{B}$ p 65 and vimentin in diabetic kidney tissues. The Nampt-NF-кB p65 and Sirt1 signaling pathway were regulated with $\mathrm{NMN}$, which participated in intervened vimentin expression in vivo. Diabetic rats were treated with NMN for 20 days. The mRNA expression analysis of Nampt, NF- $\kappa B$, Sirt1 and vimentin in diabetic rats is presented. $\beta$-actin was used as a loading control. Relative density value of PCR products=target gene grey value $/ \beta$-actin grey value. Experiments were performed in triplicate, and means \pm standard deviations of 3 experiments are presented. ${ }^{\# \#} \mathrm{P}<0.01$ vs. DN. Lane 1, DN rat; lane 2, DN rat+NMN. NMN, nicotinamide mononucleotide; Nampt, nicotinamide phosphoribosyltransferase; NF, nuclear factor; Sirt1, sirtuin 1; DN, diabetic nephropathy.

with HG control groups $(\mathrm{P}<0.01$; Fig. 11A-D) following the upregulation of endogenous Nampt (Fig. 11B). In HBZY-1 cells pretreated with $10 \mu \mathrm{mol} / 1 \mathrm{FK} 866$ under HG conditions (Fig. 11E), Nampt upregulation was significantly blocked by NMN and FK866 treatment in group 3, 4 and 5 compared with group 2 ( $\mathrm{P}<0.01$; Fig. 11E and $\mathrm{G})$, respectively. The expression 

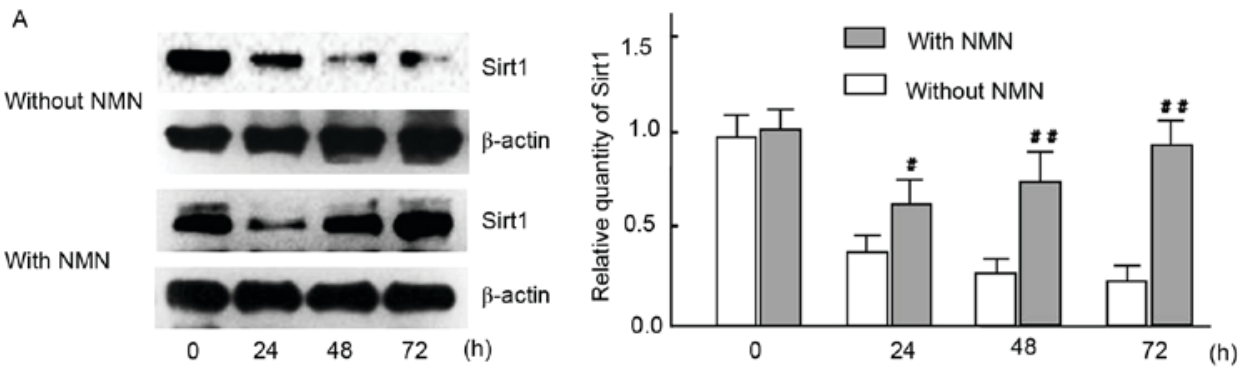

B
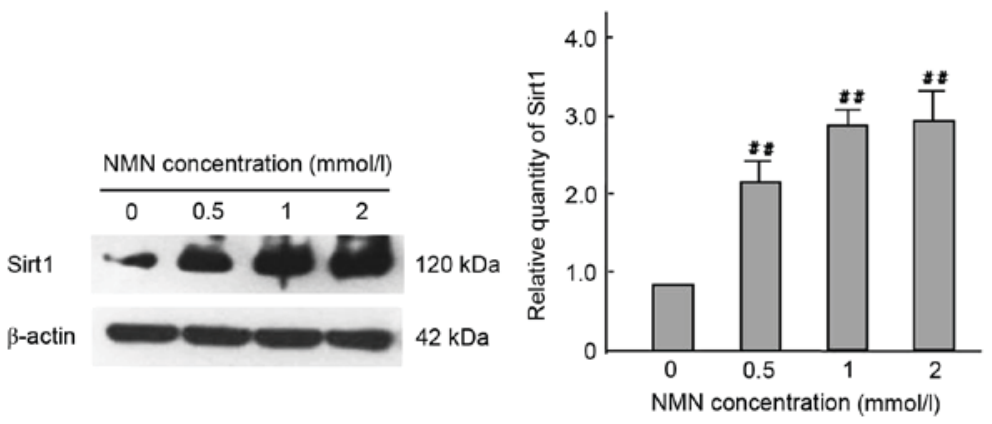

Figure 10. Effect of time- and dose-course in expression of Sirt1 with HG cultured HBZY-1 cells. (A) Cells in HG medium were treated with or without $1 \mathrm{mmol} / 1 \mathrm{NMN}$ for $0,24,48$ or $72 \mathrm{~h}$, and Sirt1 protein expression were analyzed by western blot analysis. $\beta$-actin was used as a loading control. ${ }^{*} \mathrm{P}<0.05$, ${ }^{\# \#} \mathrm{P}<0.01$ vs. without NMN. (B) Cells in HG medium were treated with $0,0.5,1$ or $2 \mathrm{mmol} / 1 \mathrm{NMN}$ for $24 \mathrm{~h}$, and Sirtl protein expression were analyzed by western blotting. $\beta$-actin was used as a loading control. ${ }^{\# \#} \mathrm{P}<0.01 \mathrm{vs.} 0 \mathrm{mmol} / \mathrm{l}$. The experiments were performed three times, and means \pm standard deviations of 3 experiments are presented. Sirt1, sirtuin 1; HG, high glucose; NMN, nicotinamide mononucleotide.

of NF-kB p65 was significantly decreased in groups 3,4 and 5 , in which expression was inhibited by both FK866 and NMN compared with group $2(\mathrm{P}<0.05$ and $\mathrm{P}<0.01$, respectively; Fig. 11E and $\mathrm{H}$ ). The expression of SIRT1 was notably increased in groups 3,4 and 5 compared with group $2(\mathrm{P}<0.05$ and $\mathrm{P}<0.01$, respectively), but it's expression was not notably changed with FK866 compared with the 5D + control group (Fig. 11E and F). These data suggest that NMN may protect HBZY-1 cells from inflammatory fibrosis in response to an HG milieu by inhibiting overexpression of endogenous Nampt and NF-kB p65, but inducing Sirt1 activation.

\section{Discussion}

Nampt has been described as a regulating factor in the cellular biosynthesis of NAD, which involves the cellular energy metabolism and oxidation-reduction systems (19). However, as an extracellular pro-inflammatory cytokine, Nampt/PBEF directly induces Toll-like receptor 4 (TLR4)-mediated NF-kBp65 activation, independently of lymphocyte antigen 96-TLR4 binding and in the absence of additional chaperones or cofactors such as lipopolysaccharide (20). The present study demonstrated that both endogenous Nampt and PARP-1 expression increased significantly in diabetic rat tissues. Notably, Yu et al (17) reported that cell damage may induce PARP-1 activation, which initiates PAR polymer formation and apoptosis-inducing factors that result in programmed necrotic cell death. This process may be a result of ATP and NAD reduction, as well as increased levels of AMP and NADH in the impaired cells.

The lack of an increase in NAD in response to the increased expression of endogenous Nampt may be attributed to the fact that an oxidative stress reaction induced by an HG milieugenerates $\mathrm{NADH}$, and thus reverses the NAD/NADH ratio.
Revollo et al (21) demonstrated the essential role of endogenous Nampt in the NAD biosynthetic pathway and implicated NAD in the regulation of glucose-stimulated insulin secretion (GSIS) in pancreatic $\beta$-cells. Accordingly, a low pancreatic level of NAD may lead to an insulin secretion defect. Benito-Martin et al (13) also reported that endogenous Nampt enzymatic activity has a key role in protecting renal cells from the adverse consequences of an inflammatory environment, such as cell death or a prolonged inflammatory response. The present study examined whether the upregulation of endogenous Nampt was able to induce glomerular cell inflammation and fibrosis in an insulin gene-mutant diabetic C57/LB6 mouse model and observed the overexpression of pro-fibrotic factors in glomerular cells. The findings suggested that severe glomerular atrophy and size reductions were observed concomitantly with endogenous Nampt upregulation when the mice suffered from DN, while fibrosis factors, including vimentin and fibronectin were over expressed following Nampt upregulation in glomerular cells of themouse kidney.

Similar results were observed in HBZY-1 cells subjected to in HG-mediated oxidative stress. The present study indicated that Nampt is an inflammatory factor and its excessive endogenous upregulation induced excessive expression of vimentin and fibronectin in glomerular cells, while Sirt1 expression reduced and NF- $\mathrm{KB}$ p 65 increased expression under oxidative stress with $\mathrm{HG}$ milieu. The results suggest that there is an association between endogenous Nampt upregulation and the fibrosis factors. The present data demonstrated these findings in vivo and in vitro using cells cultured in HG milieu and the diabetic C57/LB6 mice. The undesirable consequence may be caused by the imbalance $\mathrm{NAD}^{+} / \mathrm{NADH}$ redox in oxidative stress and the cells inflammatory response of NF- $\kappa \mathrm{B}$ p 65 over expression and activation, which promotes inflammation and fibrosis in normal cells or tissues. Previous 
A

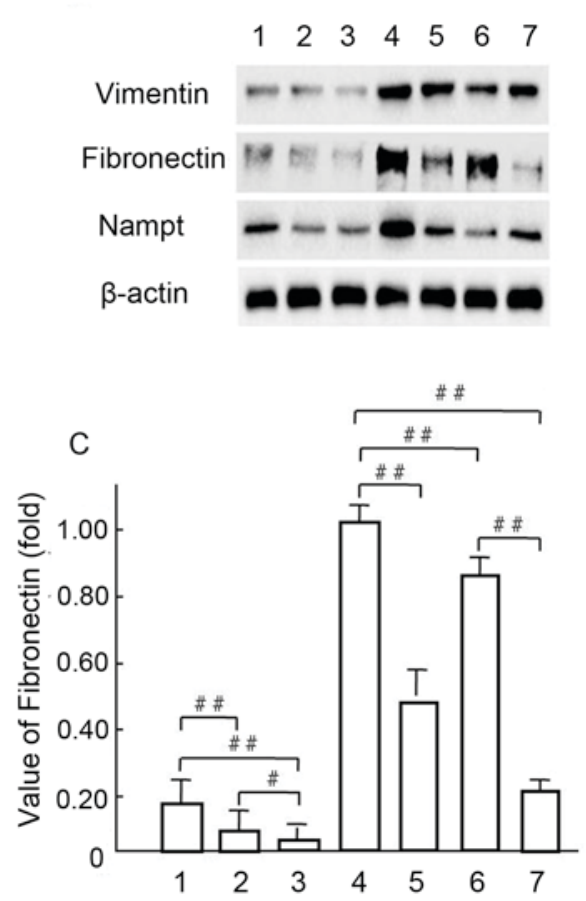

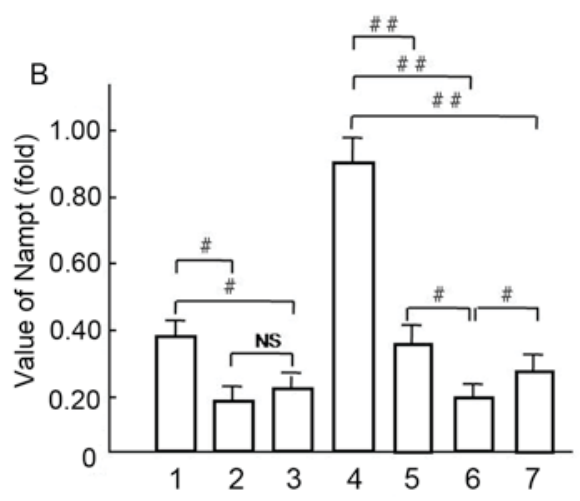

D

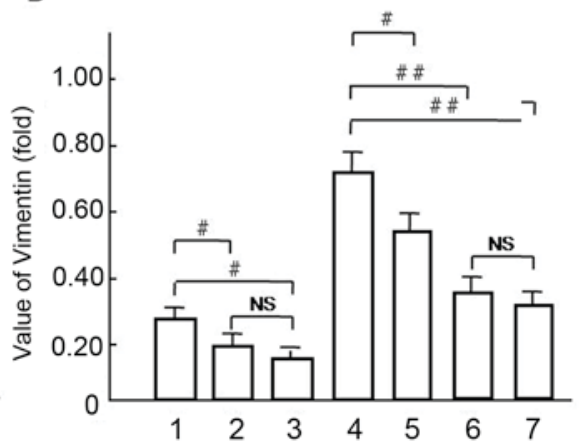



G
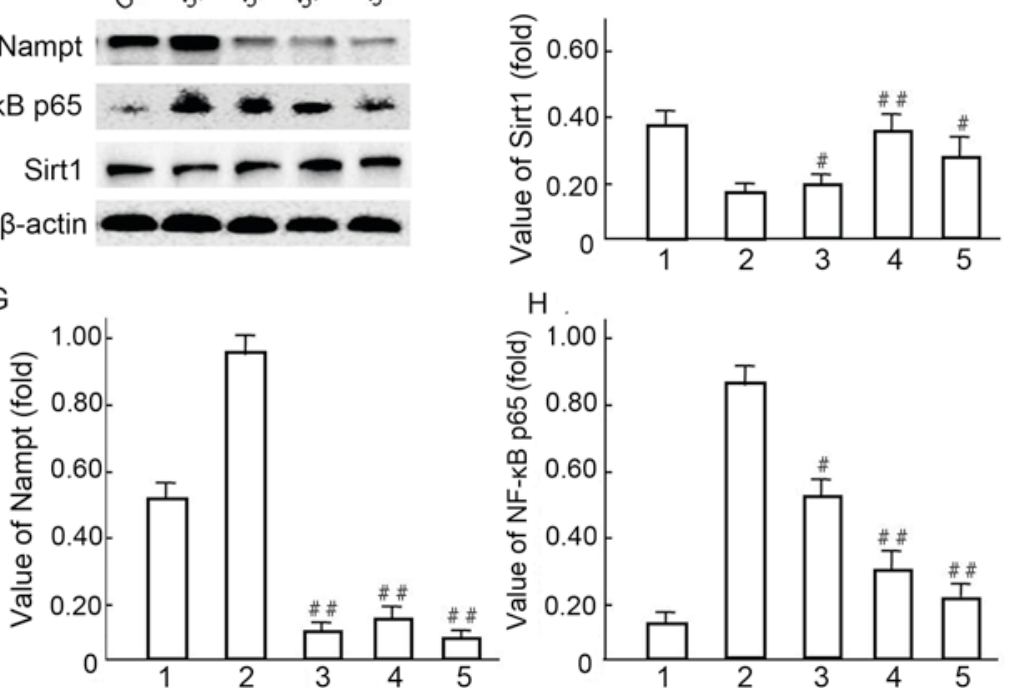

Figure 11. Vimentin and fibronectin expression levels were regulated by endogenous Nampt. (A-D) Following 5-day incubation in HG medium, HBZY-1 cells were treated with $10 \mu \mathrm{mol} / 1 \mathrm{FK} 866$ or $1 \mathrm{mmol} / 1 \mathrm{NMN}$ for a further $24 \mathrm{~h}$. Subsequently, endogenous Nampt, vimentin, fibronectin and $\beta$-actin protein expression levels were measured via western blot analysis. (A-D): 1, low glucose control group; 2, low glucose+FK866; 3, low glucose+NMN; 4, HG; 5, HG+FK866; 6, HG+NMN; 7, HG+FK866+NMN. ${ }^{~} \mathrm{P}<0.05$ and ${ }^{\# \# /} \mathrm{P}<0.01$ as indicated. (E-H) Following 4 days of incubation in HG milieu, HBZY-1 cells were treated respectively with $10 \mu \mathrm{mol} / 1 \mathrm{FK} 866$ and $1 \mathrm{mmo} / 1 \mathrm{NMN}$ for $24 \mathrm{~h}$, in which the endogenous Nampt, NF- $\mathrm{kB}$ p65, Sirt1 and $\beta$-actin protein expression levels were measured via western blot analysis. (E-H): 1, NG control group; 2, HG; 3, HG+FK866; 4, HG+NMN; 5, HG+FK866+NMN. " P $<0.05$ and ${ }^{\# \#} \mathrm{P}<0.01$ vs. 2 . Data are presented as the mean \pm standard deviations of three experiments. Each western blot experiment was performed in triplicate. NS, not significant; Nampt, nicotinamide phosphoribosyltransferase; NMN, nicotinamide mononucleotide; HG, high glucose; NF, nuclear factor; Sirt1, sirtuin 1.

studies have suggested that Sirt1 inhibition disrupted oxidative energy metabolism and stimulated NF- $\mathrm{kB}$ p65 to induce the inflammatory response characteristic of various chronic metabolic and age-associated diseases $(12,22,23)$. Notably, the $\mathrm{NF}-\kappa \mathrm{B}$ p65 signaling pathway is able to stimulate glycolytic energy flux in the context of chronic metabolic diseases, including diabetes, where as Sirt1 activation inhibits NF- $\mathrm{KB}$ p65 signaling to enhance oxidative metabolism and resolve inflammation (24). Conversely, NF-кB 65 signaling has been indicated to also downregulate Sirt1 activity by promoting the expression of microRNA-34a, interferon $\gamma$ and reactive oxygen species (12). 
In the present study, increased expression of NF- $\mathrm{kB}$ p65, FoxO1 and Bax, and decreased expression of Sirt1 were observed in response to endogenous Nampt upregulation after cells were subjected to oxidative stress in HG milieu. Endogenous Nampt expression was increased significantly in a time-dependent manner and NF- $\mathrm{KB}$ p 65 expression peaked at $72 \mathrm{~h}$, but subsequently decreased at $96 \mathrm{~h}$. Previous findings have indicated that Sirt1 has a pivotal role in cellular energy metabolism and exhibits renal protective functions through the deacetylation to regulate various factors, including the transcription factors $\mathrm{p} 53, \mathrm{NF}-\mathrm{\kappa B}$ p 65 subunit, signal transducer and activator of transcription, FoxO1, and $\mathrm{FoxO} 3$, which are associated with apoptosis, cellular aging, and inflammation (25). In addition, Sirt1 also exhibits histone deacetylation activity and exerts its renal protective effects through the epigenetic regulation of gene expression (26).

Based on the renal immunohistochemistry analysis results of diabetic rats we speculate that the glomerular inflammation and fibrosis are likely induced by endogenous Nampt overexpression. To explore this hypothesis, the cells were exposed to oxidative stress in high concentrations and were treated with FK866, a specific inhibitor of Nampt (27), and NMN, which is the product of the enzyme (28). These results also indicated that NMN activated Sirtl by increased NAD, due to inhibiting the Nampt upregulation feedback loop. This likely led to the downregulation of vimentin and fibronectin expression by interacting withNF-кB p65. Previous research has demonstrated that vimentin is associated with renal fibrosis (13). Coincidentally, the 5 ' sequence terminal of the vimentin gene includes NF- $\kappa \mathrm{B}$ p65 binding sites, in which active NF- $\kappa \mathrm{B}$ p65 just increases vimentin expression (29). Fibronectin is key protein associated with the extracellular matrix (ECM), which has a vital role in the pathogenesis of inflammatory fibrosis of DN (30). Multiple growth factor (GF) binding sites may be selected to enhance fibronectin activity to expand the collaborative ECM-GF paradigm (31). Furthermore, fibronectin involvement has been demonstrated in the reactive oxygen species/c-Jun $\mathrm{N}$-terminal kinase signaling pathway, which is associated with the NF- $\mathrm{kB}$ p65 signaling pathways (32). Abnormal upregulation of endogenous Nampt may lead to an imbalance between Sirt1 and NF-кB p65, and further aggravate cells that have been seriously damaged by oxidative stress, eventually leading to cellular dysfunction and apoptosis (33). These findings suggest that suitable horizontal gene expression of endogenous Nampt may be of the utmost importance for the physical state of the cell, whereas excess expression may promote pathological changes.

Further analysis in the present study revealed a decrease in vimentin expression in response to NMN, which may be attributed to theregulation of endogenous Nampt expression by NMN through a negative feedback pathway, as NMN is a down stream product of Nampt enzymatic activity (33). Consistent with previous findings, reduced NF- $\kappa B$ p65 expression was observed subsequent to a decrease in endogenous Nampt expression following FK866 treatment; however, Sirt1 expression was significantly increased under such conditions, which was likely due to FK866 promoting cell apoptosis directly (21). Therefore, it was speculated that in mesangial cells, synthetic endogenous Nampt may serve a pivotal role in the regulation of protein expression. However, the specific underlying mechanism remains to be elucidated. For example, the protein structure of Nampt and its regulatory mechanism are not yet understood. Furthermore, a defined amount of either endogenous or exogenous Nampt expression may affect enzyme activity in the body, but either endogenous or exogenous Nampt may lead cell to apoptosis or induce an inflammatory reaction $(33,34)$. The present results demonstrate that Nampt upregulation may lead an imbalance of Sirt1 and NF- $\mathrm{B}$ p 65 that may induce serious pathological processes, such as glomerular inflammatory fibrosis during DN.

To explore the effect of these results in the whole animal, severely diabetic rats were treated with NMN in the present study, and mRNA was isolated and measured from kidney tissues of the rats. The results indicated that the mRNA expression levels of Nampt, NF- $\mathrm{BB}$ p65 and vimentin were significantly decreased in the NMN-treated tissue, whereas Sirt1 expression was significantly increased compared with the untreated groups, respectively. The results further indicated that the Nampt-NF-kB p65 signaling pathway is likely inhibited via NMN-induced inhibition of Nampt in a negative feedback loop. This suggests that endogenous Nampt overexpression may be closely involved in the pathogenesis of glomeruli fibrosis of DN.

Together, the results of the present study provide the first evidence, to the best of our knowledge, that excess endogenous Nampt upregulation may have an important role in the pathogenesis of diabetes mellitus via the NF- $\mathrm{kB}$ p65 and Sirt1 signaling pathway. It was observed that NMN may inhibit Nampt upregulation via negative feedback regulation to indirectly inhibit NF- $\mathrm{BB}$ p65-dependent inflammatory responses in HBZY-1 cells. The effect was also reflected in enhanced Sirt1 expression, which is expected to reduce inflammatory cytokine expression. In conclusion, the present study demonstrated that NMN, a dominating product of Nampt, may act as a compensatory, protective mechanism against apoptosis and attenuate renal inflammatory fibrosis in the context of DN.

\section{Acknowledgements}

The authors wish to thank Professor Liu Ming of the Division of Metabolism, Endocrinology and Diabetes, Department of Internal Medicine, University of Michigan Medical School (Ann Arbor, MI, USA) for assisting with the preparation of histological samples, and Dr Tan Ning and Dr Xianqiong Zhou of the Experiment Center of Science, Guilin Medical University (Guilin, China) for assistance with confocal immunofluorescence analysis.

The present study was supported by grants from the Science and Technology Research Projects of Guangxi Universities (grant no. YB2014266) and the National Natural Science Foundation of China (grant nos. 31060161 and 81460164).

\section{References}

1. Aldukhayel A: Prevalence of diabetic nephropathy among Type 2 diabetic patients in some of the Arab countries. Int J Health Sci (Qassim) 11: 1-4, 2017.

2. Pofi R, Di Mario F, Gigante A, Rosato E, Isidori AM, Amoroso A, Cianci R and Barbano B: Diabetic nephropathy: Focus on current and future therapeutic strategies. Curr Drug Metab 17: 497-502, 2016. 
3. Donate-Correa J, Martin-Nunez E, Muros-de-Fuentes M, Mora-Fernandez C and Navarro-Gonzalez JF: Inflammatory cytokines in diabetic nephropathy. J Diabetes Res 2015: 948417, 2015.

4. Barutta F, Bruno G, Grimaldi S and Gruden G: Inflammation in diabetic nephropathy: Moving toward clinical biomarkers and targets for treatment. Endocrine 48: 730-742, 2015.

5. Anil Kumar P, Welsh GI, Saleem MA and Menon RK: Molecular and cellular events mediating glomerular podocyte dysfunction and depletion in diabetes mellitus. Front Endocrinol (Lausanne) 5: 151, 2014.

6. Garten A, Schuster S, Penke M, Gorski T, de Giorgis T and Kiess W: Physiological and pathophysiological roles of nampt and nad metabolism. Nat Rev Endocrinol 11: 535-546, 2015.

7. Vanden Berghe T, Kaiser WJ, Bertrand MJ and Vandenabeele P: Molecular crosstalk between apoptosis, necroptosis, and survival signaling. Mol Cell Oncol 2: e975093, 2015.

8. Fukuhara A, Matsuda M, Nishizawa M, Segawa K, Tanaka M, Kishimoto K, Matsuki Y, Murakami M, Ichisaka T, Murakami H, et al: Visfatin: A protein secreted by visceral fat that mimics the effects of insulin. Science 307: 426-430, 2005.

9. Busch F, Mobasheri A, Shayan P, Stahlmann R and Shakibaei M: Sirt-1 is required for the inhibition of apoptosis and inflammatory responses in human tenocytes. J Biol Chem 287: 25770-25781, 2012.

10. Lin Q, Geng Y, Zhao M, Lin S, Zhu Q and Tian Z: MiR-21 regulates TNF- $\alpha$-Induced CD40 expression via the SIRT1-NF- $\mathrm{BB}$ pathway in renal inner medullary collecting duct cells. Cell Physiol Biochem 41: 124-136, 2017.

11. Rubattu S, Bianchi F, Busceti CL, Cotugno M, Stanzione R, Marchitti S, Di Castro S, Madonna M, Nicoletti F and Volpe M: Differential modulation of AMPK/PPAR $\alpha / \mathrm{UCP} 2$ axis in relation to hypertension and aging in the brain, kidneys and heart of two closely related spontaneously hypertensive rat strains. Oncotarget 6: 18800-18818, 2015.

12. Kauppinen A, Suuronen T, Ojala J, Kaarniranta K and Salminen A: Antagonistic crosstalk between NF-kB and SIRT1 in the regulation of inflammation and metabolic disorders. Cell Signal 25: 1939-1948, 2013

13. Benito-Martin A, Ucero AC, Izquierdo MC, Santamaria B Picatoste B, Carrasco S, Lorenzo O, Ruiz-Ortega M, Egido J and Ortiz A: Endogenous NAMPT dampens chemokine expression and apoptotic responses in stressed tubular cells. Biochim Biophys Acta 1842: 293-303, 2014

14. Song HK, Lee MH, Kim BK, Park YG, Ko GJ, Kang YS, Han JY, Han SY, Han KH, Kim HK, et al: Visfatin: A new player in mesangial cell physiology and diabetic nephropathy. Am J Physiol Renal Physiol 295: F1485-F1494, 2008.

15. Støy J, Edghill EL, Flanagan SE, Ye H, Paz VP, Pluzhnikov A Below JE, Hayes MG, Cox NJ, Lipkind GM, et al: Insulin gene mutations as a cause of permanent neonatal diabetes. Proc Nat Acad Sci USA 104: 15040-15044, 2007.

16. Konno R, Yamakawa H, Utsunomiya H, Ito K, Sato $S$ and Yajima A: Expression of surviving and Bcl-2 in the normal human endometrium. Mol Hum Reprod 6: 529-534, 2000.

17. Yu L, Su Y, Paueksakon P, Cheng H, Chen X, Wang H, Harris RC, Zent R and Pozzi A: Integrin a1/Akita double-knockout mice on a $\mathrm{Balb} / \mathrm{c}$ background develop advanced features of human diabetic nephropathy. Kidney Int 81: 1086-1097, 2012

18. Kim BH, Lee ES, Choi R, Nawaboot J, Lee MY, Lee EY, Kim HS and Chung $\mathrm{CH}$ : Protective effects of curcumin on renaloxidative stress and lipid metabolism in a rat model of type 2 diabetic nephropathy. Yonsei Med J 57: 664-673, 2016.
19. Kover K, Tong PY, Watkins D, Clements M, Stehno-Bittel L, Novikova L, Bittel D, Kibiryeva N, Stuhlsatz J, Yan Y, et al: Expression and regulation of Nampt in human islets. PLoS One 8: e58767, 2013.

20. Camp SM,Ceco E, Evenoski CL, Danilov SM,Zhou T, Chiang ET, Moreno-Vinasco L, Mapes B, Zhao J, Gursoy G, et al: Unique toll-like receptor 4 activation by NAMPT/PBEF induces NFאB signaling and inflammatory lung injury. Sci Rep 5: 13135, 2015.

21. Revollo JR, Körner A, Mills KF, Satoh A, Wang T, Garten A, Dasgupta B, Sasaki Y, Wolberger C, Townsend RR, et al: Nampt/pbef/visfatin regulates insulin secretion in beta cells as a systemic NAD biosynthetic enzyme. Cell Metab 6: 363-375, 2007.

22. Caito S, Rajendrasozhan S, Cook S, Chung S, Yao H, Friedman AE, Brookes PS and Rahman I: SIRT1 is a redox-sensitive deacetylase that is post-translationally modified by oxidants and carbonyl stress. FASEB J 24: 3145-3159, 2010.

23. Lim JH, Lee YM, Chun YS, Chen J, Kim JE and Park JW: Sirtuin 1 modulates cellular responses to hypoxia by deacetylating hypoxia-inducible factor 1alpha. Mol Cell 38: 864-878, 2010 .

24. Salminen A, Huuskonen J, Ojala J, Kauppinen A, Kaarniranta K and Suuronen T: Activation of innate immunity system during aging: NF-kB signaling is the molecular culprit of inflamm-aging. Ageing Res Rev 7: 83-105, 2008

25. Hori YS, Kuno A, Hosoda R and Horio Y: Regulation of FOXOs and $\mathrm{p} 53$ by SIRT1 modulators under oxidative stress. PLoS One 8: e73875, 2013.

26. Wakino $\mathrm{S}$, Hasegawa $\mathrm{K}$ and Itoh $\mathrm{H}$ : Sirtuin and metabolic kidney disease. Kidney Int 88: 691-698, 2015.

27. Nakahata Y, Sahar S, Astarita G, Kaluzova M and Sassone-Corsi P: Circadian control of the NAD+ salvage pathway by CLOCK-SIRT1. Science 324: 654-657, 2009.

28. Spinnler R, Gorski T, Stolz K, Schuster S, Garten A, Beck-Sickinger AG, Engelse MA, de Koning EJ, Körner A, Kiess W, et al: The adipocytokine Nampt and its product NMN have no effect on beta-cell survival but potentiate glucose stimulated insulin secretion. PLoS One 8: e54106, 2013.

29. Lilienbaum A and Paulin D: Activation of the human vimentin gene by the Tax human T-cell leukemia virus. I. Mechanisms of regulation by the NF-kappa B transcription factor. J Biol Chem 268: 2180-2188, 1993.

30. El Mesallamy HO, Ahmed HH, Bassyouni AA and Ahmed AS: Clinical significance of inflammatory and fibrogenic cytokines in diabetic nephropathy. Clin Biochem 45: 646-650, 2012.

31. Zhu J and Clark RA: Fibronectin at select sites binds multiple growth factors (GF) and enhances their activity: Expansion of the collaborative ECM-GF paradigm. J Invest Dermatol 134: 895-901, 2014

32. Tong YF, Liu Y, Hu ZX, Li ZC and Agula A: Protocatechuic aldehyde inhibits TNF- $\alpha$-induced fibronectin expression in human umbilical vein endothelial cells via a c-Jun N-terminal kinase dependent pathway. Exp Ther Med 11: 277-282, 2016.

33. Alaee M, Khaghani S, Behroozfar K, Hesari Z, Ghorbanhosseini SS and Nourbakhsh M: Inhibition of nicotinamide phosphoribosyltransferase induces apoptosis in estrogen receptor-positive MCF-7 breast cancer cells. J Breast Cancer 20: 20-26, 2017.

34. Dahl TB, Holm S, Aukrust P and Halvorsen B: Visfatin/NAMPT: A multifaceted molecule with diverse roles in physiology and pathophysiology. Annu Rev Nutr 32: 229-243, 2012. 